\title{
High-pressure carbon monoxide preserves rat kidney grafts from apoptosis and inflammation
}

\author{
Toyofumi Abe ${ }^{1}$, Koji Yazawa ${ }^{4}$, Masayuki Fujino ${ }^{2,3}$, Ryoichi Imamura', Naoyuki Hatayama ${ }^{5}$, Yoichi Kakuta', \\ Koichi Tsutahara ${ }^{6}$, Masayoshi Okumi ${ }^{7}$, Naotsugu Ichimaru ${ }^{8}$, Jun-ya Kaimori ${ }^{8}$, Yoshitaka Isaka ${ }^{9}$, Kunihiro Seki ${ }^{10}$, \\ Shiro Takahara ${ }^{8}$, Xiao-Kang Li $^{2}$ and Norio Nonomura ${ }^{1}$
}

Renal ischemia-reperfusion (I/R) injury is unavoidable in kidney transplantation (KTX) and frequently influences both short- and long-term allograft survival. Carbon monoxide (CO) has attracted attention as a medical gas with anti-inflammatory and anti-apoptotic effects. We investigated a new strategy for organ preservation using ex vivo application of high-pressure $\mathrm{CO}$ in an experimental rat KTx model. We preserved kidney grafts using a high-pressure chamber filled with mixed gases composed of $\mathrm{CO}$ and $\mathrm{O}_{2}$. We found that cold I/R injury resulted in progressive deterioration of renal graft function in University of Wisconsin solution, whereas CO significantly improved renal function. We confirmed that $\mathrm{CO}$ decreased oxidative stress and mRNA expression of proinflammatory cytokines and inhibited tubular apoptosis in the early phases. Western blot analysis demonstrated that CO increased phosphatidylinositol-3 kinase and phosphorylation of Akt and p38 mitogen-activated protein kinase. Furthermore, CO significantly alleviated tubular injury scores and suppressed the development of interstitial fibrosis at 100 days after KTx. Thus, high-pressure mixed $\mathrm{CO}$ and $\mathrm{O}_{2}$ gases successfully preserved rat kidney grafts for $24 \mathrm{~h}$ by protecting tubular epithelial cells from apoptosis and inhibiting inflammation.

Laboratory Investigation (2017) 97, 468-477; doi:10.1038/labinvest.2016.157; published online 13 February 2017

Ischemia-reperfusion ( $\mathrm{I} / \mathrm{R})$ injury has a major role in delayed graft function and long-term changes after kidney transplantation. ${ }^{1}$ Furthermore, cold ischemic time is a potential risk factor for graft survival in recipients of kidneys from cardiac-death donors. ${ }^{2}$ A cold ischemia time of less than $12 \mathrm{~h}$ is strongly associated with superior graft survival, but few kidneys from cardiac-death donors have such a short cold ischemic time. ${ }^{3}$ Demand for kidney transplantation (KTx) far exceeds the supply of donor organs, and the shortfall is becoming more severe as donor numbers fail to keep pace with the increasing numbers of patients listed for transplantation. ${ }^{4}$ The current shortage of deceased-donor kidney grafts means that surgeons are now transplanting organs that would previously have been considered unacceptable, such as those from non-heart-beating donors. Today, there is an increasing need for solutions that afford improved protection to organs from marginal donors. Thus, new strategies to increase graft protection during cold preservation are urgently needed. ${ }^{5}$

Recently, heme oxygenase ( $\mathrm{HO}$ )-derived carbon monoxide (CO) has emerged. $\mathrm{CO}$ exerts vasoactive, anti-proliferative, antioxidant, anti-inflammatory, and anti-apoptotic effects and contributes substantially to the important role of the inducible HO-1 isoform as a mediator of tissue protection and host defense. ${ }^{6}$ Exogenous application of low doses of gaseous $\mathrm{CO}$ might provide a powerful tool to protect organs and tissues under various stressful conditions. Experimental evidence suggests a beneficial effect of gaseous $\mathrm{CO}$ under pathophysiological conditions, such as organ transplantation, I/R, inflammation, sepsis, or shock states. ${ }^{6}$ Hatayama et al performed a cervical ectopic heart transplantation after preserving a rat heart for $48 \mathrm{~h}$ using a high-pressure chamber

\footnotetext{
'Department of Specific Organ Regulation (Urology), Osaka University Graduate School of Medicine, Osaka, Japan; ${ }^{2}$ Division of Transplantation Immunology, National Research Institute for Child Health and Development, Tokyo, Japan; ${ }^{3}$ AIDS Research Center, National Institute of Infectious Diseases, Tokyo, Japan; ${ }^{4}$ Department of Urology, Osaka Medical Center and Research Institute for Maternal and Child Health, Osaka, Japan; ${ }^{5}$ Department of Anatomy, Tokyo Medical University, Tokyo, Japan; ${ }^{6}$ Department of Urology, Osaka General Medical Center, Osaka, Japan; ${ }^{7}$ Department of Urology, Tokyo Women's Medical University, Tokyo, Japan; ${ }^{8}$ Department of Advanced Technology for Transplantation, Osaka University Graduate School of Medicine, Osaka, Japan; ${ }^{9}$ Department of Nephrology, Osaka University Graduate School of Medicine, Osaka, Japan and ${ }^{10}$ High Altitude Pathology Institute, La Paz, Bolivia

Correspondence: Dr Xiao-Kang Li, MD, PhD, Division of Transplantation Immunology, National Research Institute for Child Health and Development, 2-10-1 Okura, Setagayaku, Tokyo 157-8535, Japan.

E-mail: ri-k@ncchd.go.jp
}

Received 25 July 2016; revised 6 December 2016; accepted 7 December 2016 
a

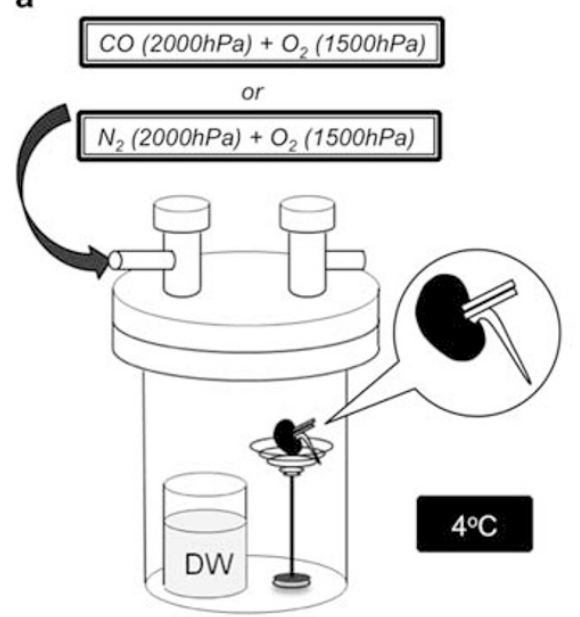

b

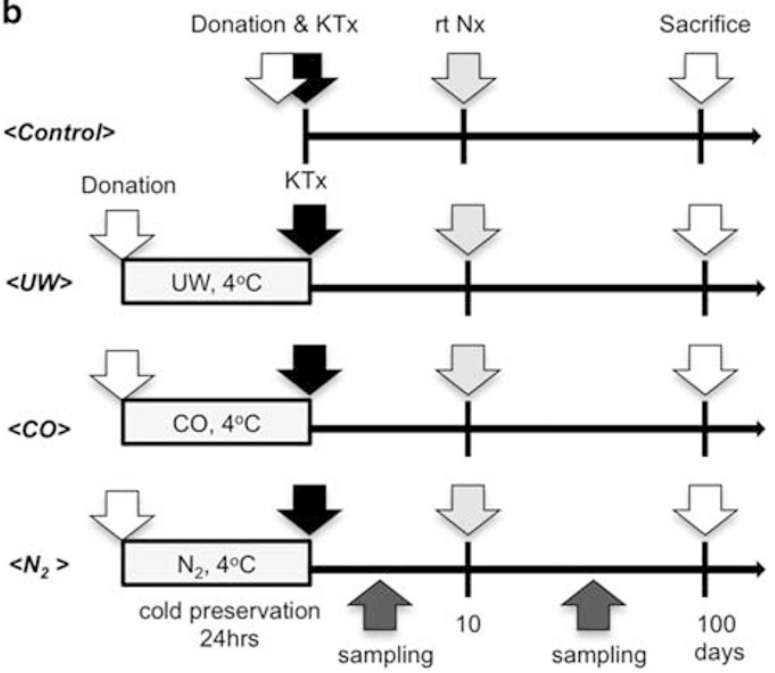

Figure 1 Illustration of a high-pressure chamber and the experimental protocols. (a) A hyperbaric chamber was used to preserve the isolated kidneys. A beaker containing distilled water (DW) was placed in the chamber to maintain the humidity inside the chamber at $>90 \%$. The kidney was flushed with University of Wisconsin (UW) solution and placed as shown in the illustration. A mixture of $\mathrm{CO}$ (or $\mathrm{N}_{2}$ ) and $\mathrm{O}_{2}$ was pressurized to $3500 \mathrm{hPa}$, and the chamber was put in a refrigerator maintained at $4{ }^{\circ} \mathrm{C}$ for $24 \mathrm{~h}$. (b) Experimental protocols. Four groups of animals were examined: recipients with nonpreserved grafts (control group), recipients with grafts preserved in UW solution for $24 \mathrm{~h}$ (UW group), and recipients with grafts preserved for $24 \mathrm{~h}$ in a high-pressure chamber containing $\mathrm{CO}$ or $\mathrm{N}_{2}$ (CO or $\mathrm{N}_{2}$ group). The blood and urine samples were collected at 30, 60 , and 90 days after kidney transplantation. Recipients were killed to obtain graft kidney samples at 3 and $24 \mathrm{~h}$, or 100 days after kidney transplantation.

filled with a mixed gas of $\mathrm{CO}(\mathrm{PCO}=4000 \mathrm{hPa})$ and $\mathrm{O}_{2}$ $\left(\mathrm{PO}_{2}=3000 \mathrm{hPa}\right)$ and confirmed resuscitation of the transplanted heart. ${ }^{7}$ The present study assumed that rat kidney grafts could be preserved under desiccating conditions with $\mathrm{CO}$ and $\mathrm{O}_{2}$ at $4{ }^{\circ} \mathrm{C}$ for $24 \mathrm{~h}$. CO protected tubular epithelial cells from apoptosis and inflammation, and thereby reduced cold I/R injury.

\section{MATERIALS AND METHODS}

\section{Animals}

Inbred male Lewis (LEW) rats, weighing 250-350 g, were purchased from SLC Japan (Hamamatsu, Japan). The animals were maintained in a controlled temperature and light environment and allowed free access to a standard diet and water throughout the experimental periods.

All studies were performed in accordance with the principles of the guidelines for animal experimentation at Osaka University and the National Research Institute for Child Health and Development.

\section{Kidney Transplantation}

Orthotopic KTx was performed using a technique described previously. ${ }^{8,9}$ Donor male LEW rats were anesthetized with $50 \mathrm{mg} / \mathrm{kg}$ pentobarbital sodium (Nembutal, Abbott Laboratories, Chicago, IL, USA) and heparinized with 500 U/body heparin before surgery. Anesthetized animals were subjected to a midline laparotomy. The left kidney was flushed with icecold University of Wisconsin (UW) solution (Viaspan, DuPont, Wilmington, DE, USA) via the abdominal aorta and was removed. The excised graft was preserved in UW solution or in a high-pressure chamber filled with mixed gas at $4{ }^{\circ} \mathrm{C}$ for $24 \mathrm{~h}$. After a left nephrectomy on a similarly anesthetized recipient LEW rat, the kidney graft was transplanted orthotopically into the recipient by end-to-end anastomosis of the left renal vessels and ureter with 10-0 sutures using microsurgical techniques. The remaining right native kidney was removed 10 days after KTx for experiments to assess renal function.

\section{Ex Vivo Application of Mixed High-Pressure Gas during Cold Preservation}

The isolated kidney was placed in a high-pressure chamber without preservation solution, which was cooled beforehand to $4{ }^{\circ} \mathrm{C}$ (refs 7,10,11; Figure 1a). Subsequently, the highpressure chamber was filled with mixed gas composed of $\mathrm{CO}$ $(\mathrm{PCO}=2000 \mathrm{hPa})$ and $\mathrm{O}_{2} \quad\left(\mathrm{PO}_{2}=1500 \mathrm{hPa}\right)$ or $\mathrm{N}_{2}$ $\left(\mathrm{PN}_{2}=2000 \mathrm{hPa}\right)$ and $\mathrm{O}_{2}\left(\mathrm{PO}_{2}=1500 \mathrm{hPa}\right)$. After preservation at $4{ }^{\circ} \mathrm{C}$ for $24 \mathrm{~h}$, the kidney graft was removed from the chamber, and an orthotopic KTx was performed.

\section{Experimental Protocols}

Syngeneic KTx was performed, and four groups of animals were examined: recipients with non-preserved grafts (control group), recipients with grafts preserved in UW solution for $24 \mathrm{~h}$ (UW group), and recipients with grafts preserved for $24 \mathrm{~h}$ in a high-pressure chamber containing $\mathrm{CO}$ or $\mathrm{N}_{2}$ ( $\mathrm{CO}$ or $\mathrm{N}_{2}$ group; Figure 1b). Blood and urine were obtained at 30, 60, and 90 days after KTx. Recipients were killed at 3, $24 \mathrm{~h}$, and 100 days after KTx, and the kidneys were removed after perfusion with $20 \mathrm{ml}$ of ice-cold PBS. The cortex was carefully 
dissected from the medulla and then processed for evaluation by mRNA and protein analysis. Tissues for mRNA and protein extraction were frozen using liquid nitrogen, and tissues for light microscopy were fixed with $4 \%$ paraformaldehyde (PFA) overnight, dehydrated through a graded ethanol series, and embedded in paraffin.

\section{Assessment of Carboxyhemoglobin (CO-Hb) by Blood Gas Analysis}

Arterial blood was obtained from naive LEW rats and COtreated recipients at 3 and $24 \mathrm{~h}$ after KTx. $\mathrm{CO}-\mathrm{Hb}$ was analyzed with a blood gas analyzer (ABL735, Radiometer, Brønshøj, Denmark).

\section{Renal Function}

Serum creatinine $(\mathrm{Cr})$ and blood urea nitrogen (BUN) levels were measured by the creatinase-peroxidase method and the urease-ultraviolet method, respectively (SRL, Tokyo, Japan). Protein and Cr levels in $24 \mathrm{~h}$ urine samples were determined using a metabolic cage system. The formula for creatinine clearance is: $(\mathrm{CCr} ; \mathrm{ml} / \mathrm{min})=(\mathrm{U}[\mathrm{Cr}] \times$ urine volume $) /(\mathrm{S}$ $[\mathrm{Cr}] \times$ time), where $\mathrm{U}[\mathrm{Cr}]$ is urinary creatinine $(\mathrm{mg} / \mathrm{dl})$, urine volume is in milliliters, and $\mathrm{S}[\mathrm{Cr}]$ is serum creatinine $(\mathrm{mg} / \mathrm{dl})$.

\section{Morphological Analysis}

Tissue samples were fixed in 4\% PFA for $24 \mathrm{~h}$ and embedded in paraffin. Then, $3-\mu \mathrm{m}$ tissue sections were mounted on saline (2\% 3-aminopropyltriethoxysilane)-coated slides and deparaffinized with xylene. Histological sections were stained with periodic acid-Schiff (PAS) and Masson's trichrome stains. Tubular injury was scored by estimating the percentage of tubules in the outer medulla and corticomedullary junction that showed epithelial necrosis or had necrotic debris or cast as follows: 0 , none; $1+,<10 \% ; 2+, 10-25 \% ; 3+, 26-45 \%$; $4+$, $46-75 \% ; 5+,>75 \% .^{12}$ Ten viewing fields randomly selected from the outer medulla and corticomedullary junction on each slide section were examined at $\times 200$ magnification. The interstitial fibrotic area was stained blue with Masson's trichrome staining, and a color image analyzer (WinROOF, ver. 5.5, MITANI, Tokyo, Japan) estimated the area quantitatively. All histological slides were examined by light microscopy using a Nikon Eclipse 80i (Nikon, Tokyo, Japan); pictures were taken with Nikon ACT-1 (ver. 2.63). The scores of 10 fields per kidney were averaged, and the mean scores for each group were averaged.

\section{TUNEL Staining}

Terminal deoxynucleotidyltransferase-mediated dUTP nick end-labeling (TUNEL) staining was performed using the in situ Apoptosis Detection Kit (Takara Bio, Ohtsu, Japan), according to the manufacturer's instructions. Briefly, the sections were deparaffinized and treated with proteinase $\mathrm{K}$ $(10 \mu \mathrm{g} / \mathrm{ml}$, Takara Bio) for $15 \mathrm{~min}$ at room temperature. The slides were then incubated with peroxidase blocking solution
(Dako, Hamburg, Germany) for $10 \mathrm{~min}$, followed by incubation in TdT enzyme solution for $60 \mathrm{~min}$ at $37^{\circ} \mathrm{C}$. The reaction was terminated by incubating in a stop/wash buffer for $30 \mathrm{~min}$ at $37^{\circ} \mathrm{C}$. Chromogenic color was developed with DAB (Dako), and the nuclei were counterstained with hematoxylin. The number of TUNEL-positive cell nuclei was counted in 10 random high-power fields $(\times 200)$ of each slide and averaged.

\section{Antibodies and Western Blot Analysis}

The following antibodies were used for immunochemical testing to detect the pathways protecting the kidneys: polyclonal phosphatidylinositol-3 kinase (PI3K) p85a antibody, polyclonal phospho-Akt (Ser473) antibody, polyclonal phospho-p38 mitogen-actiated protein kinase (MAPK; Thr180/Tyr 182) antibody, polyclonal phospho-p44/42 MAPK (Erk1/2; Thr202/Tyr204) antibody, and polyclonal phosphostress-activated protein kinase (SAPK)/c-jun N-terminal kinase (JNK; Thr183/Tyr185) antibody (1:10000, Cell Signaling Technology, Beverly, MA, USA). Protein levels were normalized with polyclonal $\beta$-actin antibody $(1: 10000$, Cell Signaling Technology).

Kidney tissue was homogenized in radioimmunoprecipitation lysis buffer with phenylmethylsulfonylfluoride solution, sodium orthovanadate solution, protease inhibitor (Santa Cruz Biotechnology, Santa Cruz, CA, USA), and phosphatase inhibitor (Sigma-Aldrich, St Louis, MO, USA). Homogenates were centrifuged $\left(12000 \mathrm{~g}, 10 \mathrm{~min}, 4^{\circ} \mathrm{C}\right)$, and the supernatant total protein was measured using the Lowry protein assay (Bio-Rad Laboratories, Hercules, CA, USA). Total protein lysates $(15 \mu \mathrm{g})$, containing 1:1 denaturing sample buffer, were boiled for $3 \mathrm{~min}$, resolved on 10\% SDS-polyacrylamide gels, and electrophoretically transferred to a PVDF membrane (Bio-Rad). The filter was blocked with 2\% ECL Advance Blocking Agent (Amersham Bioscience, Piscataway, NJ, USA) in $10 \mathrm{mM}$ Tris-buffered saline with $0.1 \%$ Tween 20 (TBS-T), followed by an overnight incubation at $4{ }^{\circ} \mathrm{C}$ with diluted primary antibodies in blocking buffer. After washing six times in TBS-T, the filter was incubated with secondary antibody (1:10 000; Cell Signaling Technology) in blocking buffer for $60 \mathrm{~min}$ at room temperature and developed to detect specific protein bands using ChemiDocXRS (Bio-Rad) and ECL Advance Reagents (Amersham Bioscience).

\section{RNA Isolation and Quantitative Real-Time RT-PCR}

Total RNA was extracted from kidney grafts using an RNeasy Mini Kit (QIAGEN, Valencia, CA, USA), according to the manufacturer's protocol. Total RNA was determined by measuring the optical density at $260 \mathrm{~nm}$. Each $600 \mathrm{ng}$ of RNA was reverse transcribed to cDNA using oligo(dT) primers and SuperScript reverse transcriptase (Invitrogen, Carlsbad, CA, USA), according to the manufacturer's protocol. Quantitative RT-PCR was performed using the TaqMan program on an Applied Biosystems 7900HT Sequence Detection System (Applied Biosystems, Foster City, CA, USA). Primers amplifying the rat mRNA regions and a specific Taqman 
probe were designed using the Primer Express software package (Applied Biosystems). Data are expressed as the comparative cycle threshold $(\mathrm{Ct})$. The normalized $\mathrm{Ct}$ value of each gene was obtained by subtracting the $\mathrm{Ct}$ value of $18 \mathrm{~s}$ rRNA. The fold change vs one sample of the control group was calculated as described previously. ${ }^{13}$

\section{Oxidative Damage Measurement}

The oxidative stress marker 8-hydroxydeoxyguanosine (8OHdG) was measured with an enzyme-linked immunosorbent assay kit (Japan Institute for the Control of Aging, Shizuoka, Japan), according to the manufacturer's instructions. 8-OHdG, a product of oxidatively damaged DNA, was detected using a competitive enzyme-linked immunosorbent assay using a monoclonal antibody (clone N45.1) that is specific for DNA damage.

\section{Statistical Analysis}

Data are expressed as means \pm s.d. The Kaplan-Meier method was used to calculate survival rates after KTx. Log-rank tests were used for comparisons between the two groups. Statistical analysis was performed using Fisher's LSD test and Tukey test for parametric multiple comparisons. Differences were considered statistically significant at $P<0.05$.

\section{RESULTS}

\section{Recipient Survival Rates}

Figure $2 \mathrm{a}$ and $\mathrm{b}$ shows the recipient survival rates assessed at 100 days after KTx. We performed an orthotopic KTx after preserving a rat kidney for $24 \mathrm{~h}$ using a high-pressure chamber filled with a mixed gas of $\mathrm{CO}(\mathrm{PCO}=4000 \mathrm{hPa})$ and $\mathrm{O}_{2}\left(\mathrm{PO}_{2}=3000 \mathrm{hPa}\right)$ according to the previous study in a cervical ectopic heart transplantation model. ${ }^{7}$ However, no protective effect of high-pressure $\mathrm{CO}(\mathrm{PCO}=4000 \mathrm{hPa})$ and $\mathrm{O}_{2}\left(\mathrm{PO}_{2}=3000 \mathrm{hPa}\right)$ was observed compared with the group preserving a rat kidney for $24 \mathrm{~h}$ in a chamber that was filled with room air $(1000 \mathrm{hPa})$. Then, we selected a lower mixed gas composed of $\mathrm{CO} \quad(\mathrm{PCO}=2000 \mathrm{hPa})$ and $\mathrm{O}_{2}$ $\left(\mathrm{PO}_{2}=1500 \mathrm{hPa}\right)$ for kidney graft, resulting in improved graft survival (Figure 2a). Next, four groups of animals were examined: recipients with non-preserved grafts (control group), recipients with grafts preserved in UW solution for $24 \mathrm{~h}$ (UW group), and recipients with grafts preserved for $24 \mathrm{~h}$ in a high-pressure chamber containing $\mathrm{CO}$ $(\mathrm{PCO}=2000 \mathrm{hPa}, \mathrm{CO}$ group $)$ and $\mathrm{O}_{2}\left(\mathrm{PO}_{2}=1500 \mathrm{hPa}\right)$, or $\mathrm{N}_{2}\left(\mathrm{PN}_{2}=2000 \mathrm{hPa}, \mathrm{N}_{2}\right.$ group $)$ and $\mathrm{O}_{2}\left(\mathrm{PO}_{2}=1500 \mathrm{hPa}\right)$. No significant difference was observed among the non-preserved control group ( $100 \%, n=10)$, UW group $(78.6 \%, n=14)$, CO group $(84.6 \%, n=13)$, or $\mathrm{N}_{2}$ group $(71.1 \%, n=9)$.
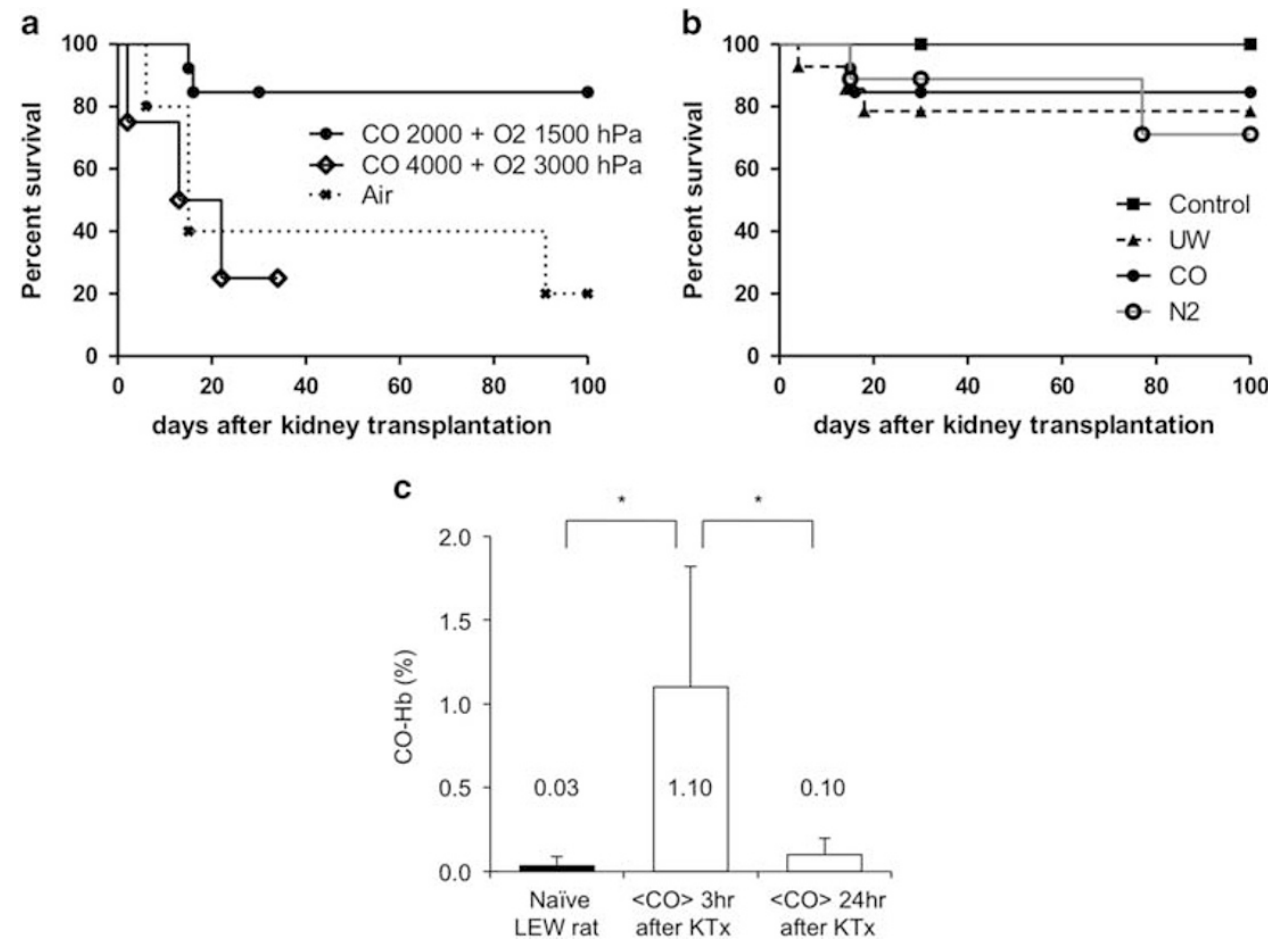

Figure 2 Recipient survival rates and percent carboxyhemoglobin (CO-Hb). Recipient survival rates were assessed by following animals for 100 days after transplantation. (a) An orthotopic KTx was performed after preserving a rat kidney for $24 \mathrm{~h}$ using a chamber filled with a mixed gas of $\mathrm{CO}$ $(\mathrm{PCO}=4000 \mathrm{hPa})$ and $\mathrm{O}_{2}\left(\mathrm{PO}_{2}=3000 \mathrm{hPa} ; n=4\right), \mathrm{CO}(\mathrm{PCO}=2000 \mathrm{hPa})$ and $\mathrm{O}_{2}\left(\mathrm{PO}_{2}=1500 \mathrm{hPa} ; n=14\right)$, or room air $(1000 \mathrm{hPa} ; n=5)$. (b) No significant differences were observed among the control $(n=10)$, UW $(n=14), \mathrm{CO}\left(\mathrm{PCO}=2000 \mathrm{hPa}+\mathrm{PO}_{2}=1500 \mathrm{hPa}, n=13\right)$, and $\mathrm{N}_{2}\left(\mathrm{PN}_{2}=2000 \mathrm{hPa}+\mathrm{PO} 2=1500 \mathrm{hPa}\right.$, $n=9$ ) groups. (c) Percent $\mathrm{CO}-\mathrm{Hb}$ in the blood of naive Lewis rats and recipients with CO-treated grafts at 3 and $24 \mathrm{~h}$ after kidney transplantation ( $n=3$ / group). Fisher's LSD test, ${ }^{*} P<0.05$. 
a

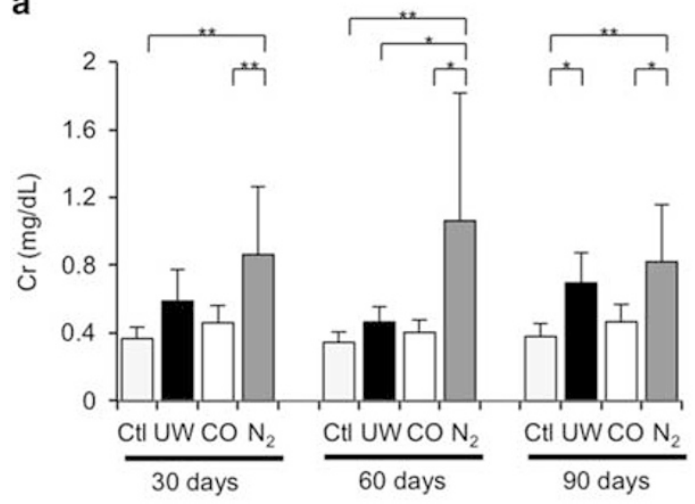

b

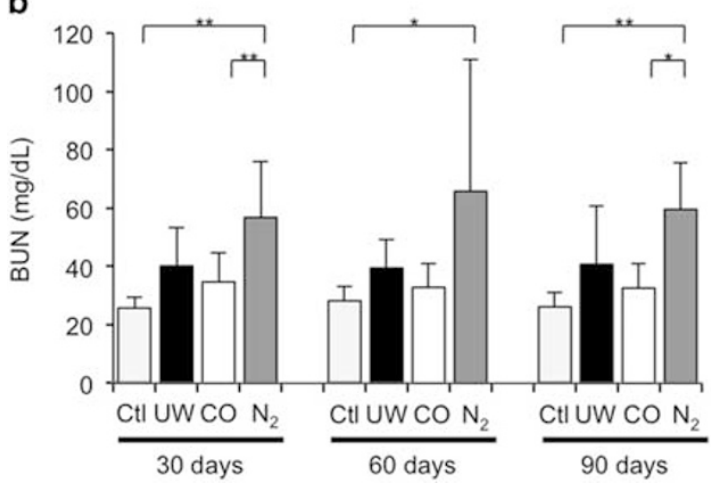

C

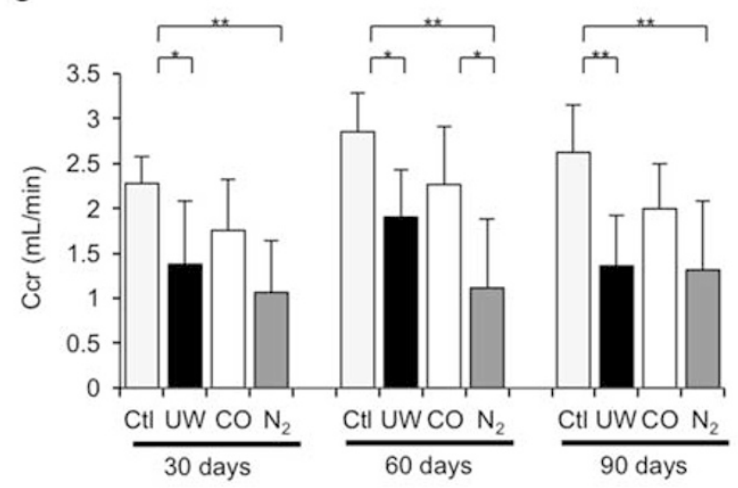

d

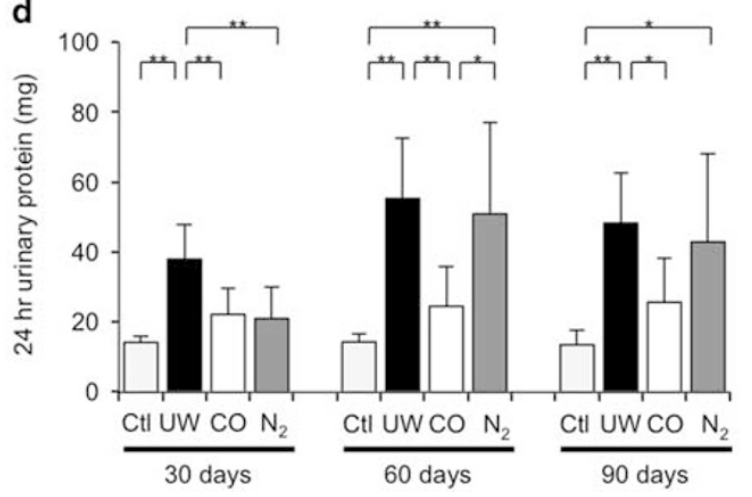

Figure 3 Carbon monoxide protects renal function. Renal graft function was assessed by serum creatinine (a), blood urea nitrogen (b), creatinine clearance $(\mathrm{CCr})(\mathbf{c})$, and $24 \mathrm{~h}$ urine protein (d) at 30,60, and 90 days after kidney transplantation (KTx). The syngenic KTx procedure without cold preservation did not affect graft function, whereas prolonged cold ischemia for $24 \mathrm{~h}$ resulted in a decrease in $\mathrm{CCr}$ with considerable proteinuria. The ex vivo application of high-pressure CO significantly improved graft function compared with the UW and $\mathrm{N}_{2}$ groups. Tukey's test, ${ }^{* *} P<0.01,{ }^{*} P<0.05$.

\section{Effect of Carbon Monoxide on CO-Hb}

The ex vivo application of high-pressure $\mathrm{CO}$ significantly increased recipient $\mathrm{CO}-\mathrm{Hb}$ levels to $1.10 \pm 0.72 \%$ at $3 \mathrm{~h}$ after KTx compared with naive LEW rats $(0.03 \pm 0.06 \%, P<0.05$; Figure 2c). At $24 \mathrm{~h}$ after $\mathrm{KTx}, \mathrm{CO}-\mathrm{Hb}$ levels returned to $0.10 \pm 0.10 \%(P<0.05$ vs $3 \mathrm{~h}$ after KTx $)$.

\section{Effect of Carbon Monoxide on Renal Function}

Figure 3 summarizes the effects of $\mathrm{CO}$ on renal function in the rat KTx models. Although no significant difference was observed in survival rates among the experimental groups, cold I/R injury resulted in progressive deterioration of renal graft function. Treatment with $\mathrm{CO}$, but not $\mathrm{N}_{2}$, significantly suppressed the increase in $\mathrm{Cr}$ and BUN at 30, 60, and 90 days after KTx (Figure $3 \mathrm{a}$ and b). CCr significantly decreased to $1.90 \pm 0.53 \mathrm{ml} / \mathrm{min}$ in the UW-preserved group at 60 days after KTx ( $v s$ control group, $2.86 \pm 0.44 \mathrm{ml} / \mathrm{min} ; P<0.01$; Figure $3 \mathrm{c}$ ). In contrast, treatment with $\mathrm{CO}$ maintained the CCr level $(2.27 \pm 0.65 \mathrm{ml} / \mathrm{min}$; not significant $v$ s control group), while $\mathrm{N}_{2}$ failed $(1.12 \pm 0.77 \mathrm{ml} / \mathrm{min} ; P<0.01$ vs $\mathrm{CO}$ group). Furthermore, recipients in the UW group exhibited significant proteinuria $(55.3 \pm 17.1 \mathrm{mg}$ per $24 \mathrm{~h})$ at 60 days after KTx, compared with control rats $(14.3 \pm 2.5 \mathrm{mg}$ per $24 \mathrm{~h}$; Figure 3d). Recipients in the $\mathrm{CO}$ group showed significantly lower protein excretion $(24.5 \pm 11.2 \mathrm{mg}$ per $24 \mathrm{~h} ; P<0.01$ vs UW group), whereas those in the $\mathrm{N}_{2}$ group did not $(50.9 \pm 26.0 \mathrm{mg}$ per $24 \mathrm{~h}$; not significant $v s \mathrm{UW}$ group).

\section{Effect of Carbon Monoxide on Tubular Injury and Interstitial Fibrosis}

PAS staining revealed that cold I/R injury induced characteristic histological changes, including tubular atrophy and dilation, loss of the brush border, inflammatory cell infiltration, and cast formation at 100 days after KTx (Figure 4a). However, CO treatment significantly alleviated tubular injury scores compared with the UW and $\mathrm{N}_{2}$ groups (Figure $4 \mathrm{~b}$ ). The interstitial fibrotic area was stained blue with Masson's trichrome staining (Figure 4c), and a color image analyzer was used to estimate the area quantitatively (Figure $4 \mathrm{~d}$ ). The UW and $\mathrm{N}_{2}$ groups showed a progression of interstitial fibrosis. In parallel with the PAS staining findings, CO treatment significantly ameliorated the development of interstitial fibrosis.

\section{Morphological Evidence of Apoptosis}

To investigate whether $\mathrm{CO}$ treatment could protect tubular cells from apoptosis, the apoptotic bodies, labeled as an in situ 
a

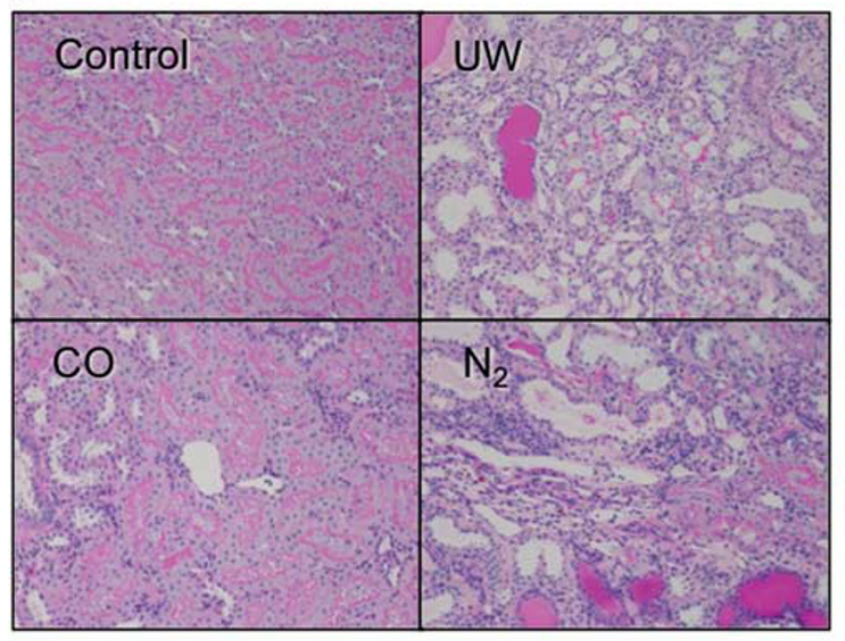

b

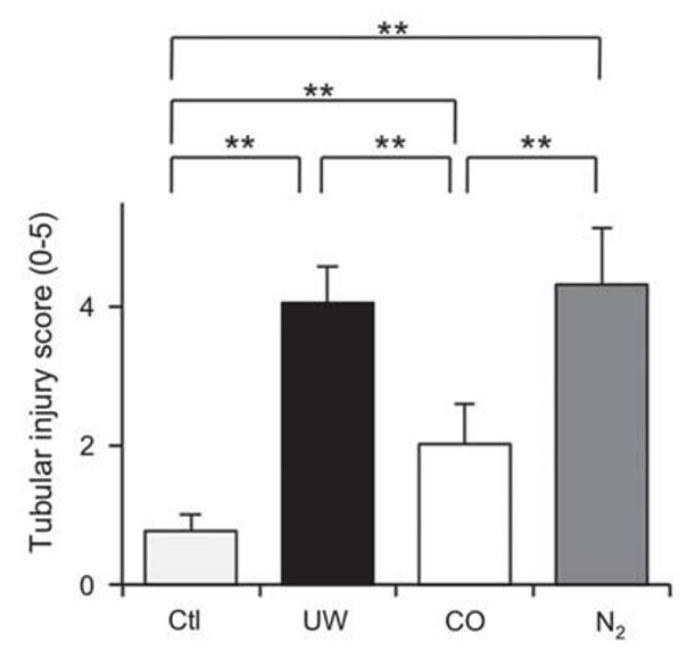

C

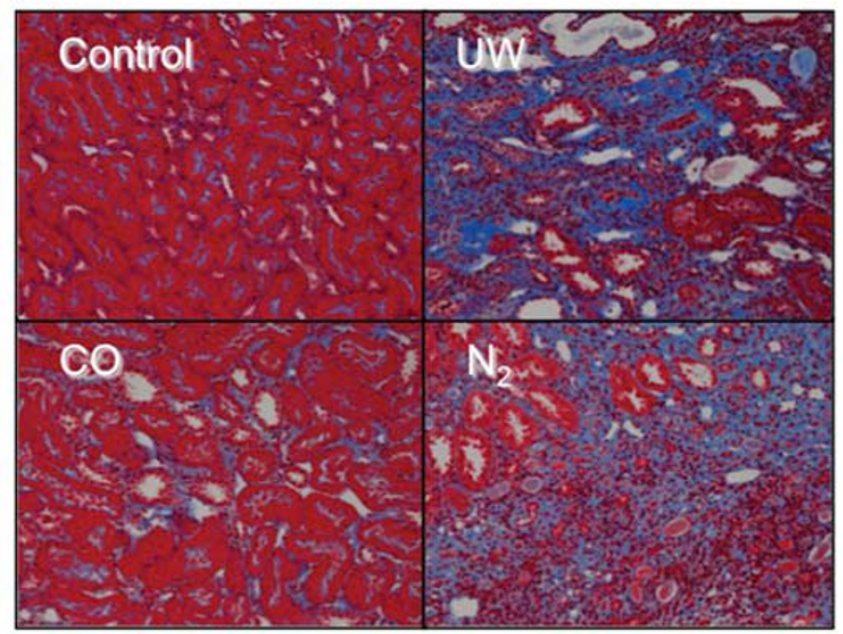

d

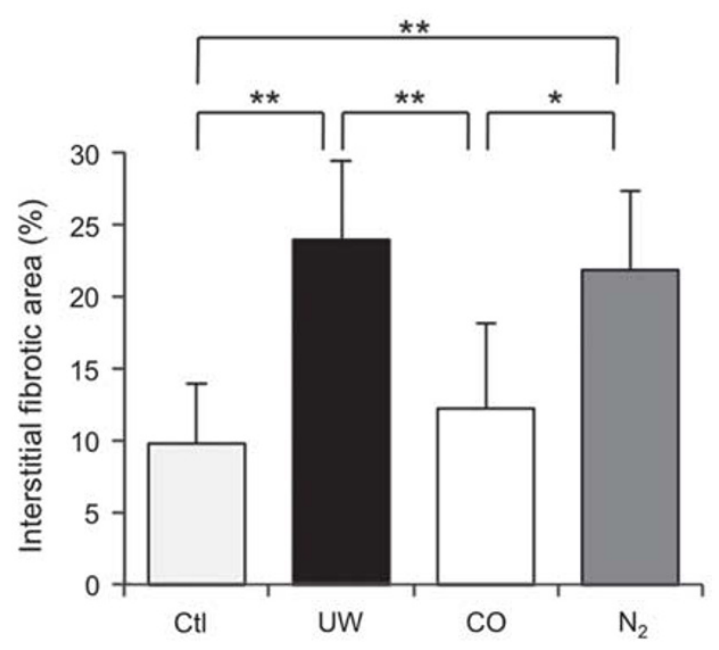

Figure 4 Renal histopathological findings. Representative photomicrographs show the renal morphological changes seen on periodic acid-Schiff (PAS) staining (a) and Masson's trichrome staining (c) at 100 days after kidney transplantation. Quantitative analysis of tubular injury with PAS staining (b) and interstitial fibrosis with Masson's trichrome staining (d) are summarized. The data are expressed as means \pm s.d. Tukey's test, ${ }^{* *} P<0.01,{ }^{*} P<0.05$.

end-labeled DNA fragment with the TUNEL method, were examined during the early phases (Figure 5). Tubular apoptosis increased persistently after cold $\mathrm{I} / \mathrm{R}$ injury in the UW-preserved kidneys $(14.4 \pm 4.8,24.1 \pm 4.0$, and $14.2 \pm 5.0$ cells per high-power field, at the end of cold storage, 3 and $24 \mathrm{~h}$ after KTx, respectively). Treatment with CO significantly repressed tubular apoptosis $(1.5 \pm 0.6,4.8 \pm 2.1$, and $4.4 \pm 2.7$ cells per high-power field, at the end of cold storage, 3 and $24 \mathrm{~h}$ after $\mathrm{KTx}$, respectively), whereas $\mathrm{N}_{2}$ did not $(14.7 \pm 6.5$, $22.5 \pm 0.6$, and $21.5 \pm 2.2$ cells per high-power field, at the end of cold storage, 3 and $24 \mathrm{~h}$ after KTx, respectively).

\section{Effect of Carbon Monoxide on Cell Signaling}

Cortical expression of the PI3K-Akt and MAPK pathways was examined to elucidate the intracellular signaling implicated in tubular protection (Figure 6). A western blot analysis demonstrated that treatment with $\mathrm{CO}$ increased PI3K and
Akt phosphorylation in the early phases after KTx. Furthermore, CO selectively activated p38 MAPK but had no effect on ERK1/ERK2 or JNK MAP kinases.

\section{Cortical Tissue mRNA Expression}

As shown in Figure 7, a real-time RT-PCR analysis demonstrated that $\mathrm{CO}$ treatment decreased interferon (IFN)- $\gamma$ at $3 \mathrm{~h}$ after KTx $(P<0.05)$ and inducible nitric oxide synthase (iNOS) mRNA levels at $24 \mathrm{~h}$ after KTx $(P<0.01)$ compared with simple cold storage using UW solution. We also assessed activation of the heme-degrading enzyme HO-1, which has a primary role in eliminating toxic free heme and protects cells from heme-induced oxidative stress. ${ }^{14} \mathrm{HO}-1$ mRNA levels in the kidney grafts were elevated $24 \mathrm{~h}$ after KTx in the UW group, whereas the mixed gas treatment significantly reduced HO-1 mRNA levels $(P<0.01)$. 
a

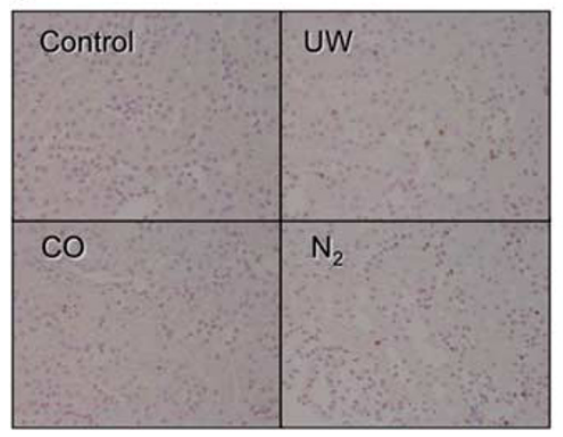

b

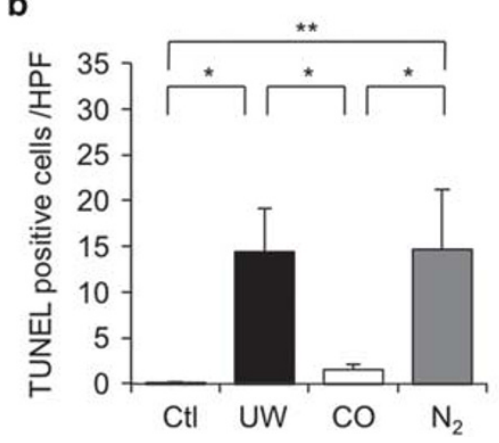

c

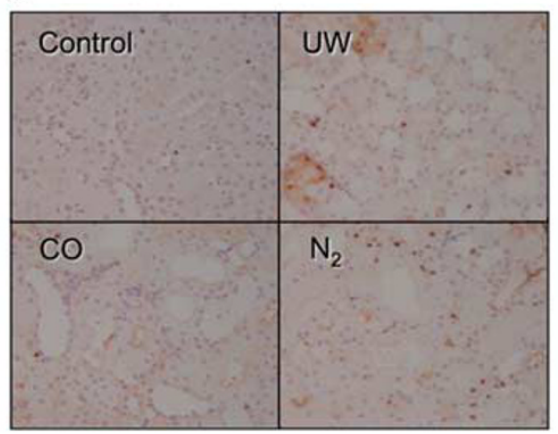

d

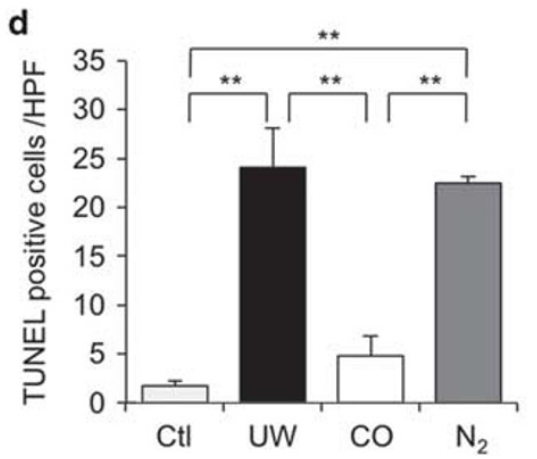

e

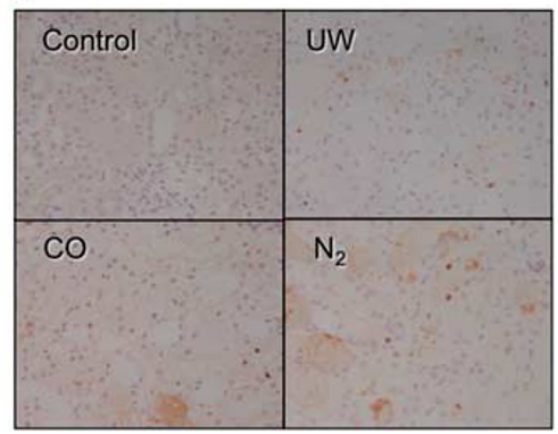

f

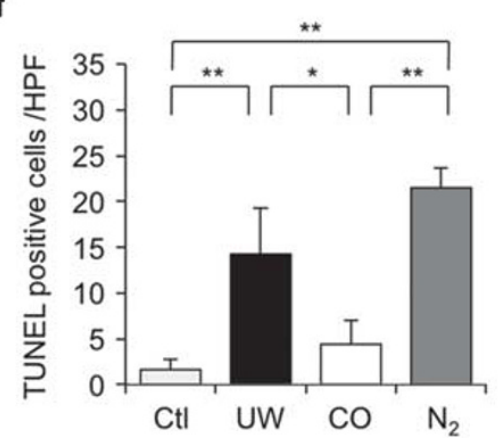

Figure 5 Carbon monoxide decreases tubular apoptosis. Many TUNEL-positive cells were detected in the outer medulla following prolonged cold ischemia for $24 \mathrm{~h}$ and were suppressed by CO treatment at the end of cold storage (a), 3 (c) and $24 \mathrm{~h}$ after kidney transplantation (e). TUNEL-positive cells $(\mathbf{b}, \mathbf{d}, \mathbf{f})$ were counted in tubular cells of the outer medulla at $\times 200$ magnification in a minimum of 10 fields $(n=3 / g r o u p)$. Data are expressed as means \pm s.d. Tukey's test, ${ }^{* *} P<0.01,{ }^{*} P<0.05$.

\section{Effects of Carbon Monoxide on Oxidative Stress}

Serum levels of 8 -OHdG were examined to evaluate the effects of $\mathrm{CO}$ on oxidative stress (Figure 8). Prolonged cold ischemia for $24 \mathrm{~h}$ resulted in an increase in serum 8-OHdG levels at $3 \mathrm{~h}$ after KTx $(0.22 \pm 0.05 \mathrm{ng} / \mathrm{ml}$ in the control group, $0.32 \pm 0.10 \mathrm{ng} / \mathrm{ml}$ in the UW group, and $0.29 \pm 0.04 \mathrm{ng} / \mathrm{ml}$ in the $\mathrm{N}_{2}$ group), whereas $\mathrm{CO}$ treatment ameliorated oxidative DNA injury $(0.22 \pm 0.03 \mathrm{ng} / \mathrm{ml})$.

\section{DISCUSSION}

We developed a new strategy to preserve organs using highpressure CO. Previous studies have reported successful organ preservation using a high-pressure chamber filled with a mixed gas in a cervical ectopic heart transplantation model. ${ }^{7,10,11}$ Here, we evaluated long-term graft function after preserving the graft using this method in a rat kidney transplantation model as a life-supporting model.

CO has anti-inflammatory and anti-apoptotic effects and has attracted attention as a medical gas. ${ }^{15}$ Zhang et al ${ }^{16}$ demonstrated that the anti-apoptotic effects of CO involve both the PI3K/Akt and p38 MAPK signaling pathways in endothelial cells in an anoxia-reoxygenation injury model. Nakao and colleagues also demonstrated that lowconcentration $\mathrm{CO}$ inhalation provided protection against cold I/R injury in a rat kidney transplantation model. ${ }^{17}$ Similar protective results can be achieved after storage of grafts in a UW solution saturated with CO. ${ }^{18,19}$ Sener et al ${ }^{20}$ demonstrated that carbon monoxide releasing molecules (CORM) supplementation in UW solution has a significant impact on decreasing cellular and graft injury, and improving rat kidney graft survival through its anti-apoptotic effects. Recently, Ruan Y et al ${ }^{21}$ reported the protective effect of $\mathrm{CO}$ from CORM on renal ischemia-reperfusion injury is associated with the inhibition of high-mobility group box 1 (HMGB1) translocation and release. In addition to its antiinflammatory and anti-apoptotic effects, $\mathrm{CO}$ reduced graft immunogenicity and inhibited chronic allograft nephropathy in a rat kidney transplantation model. ${ }^{22}$ Although CO may cause serious adverse effects, these results indicate that $\mathrm{CO}$ is a possible therapeutic tool for deceased-donor organ transplantation.

Cold I/R injury resulted in progressive deterioration of renal graft function, whereas ex vivo application of highpressure CO gas significantly improved renal function compared with simple cold storage using UW solution (Figure 3). This finding was confirmed by our observation that replacing $\mathrm{CO}$ with $\mathrm{N}_{2}$ resulted in a loss of the protective effect. Histopathologically, CO treatment significantly alleviated tubular injury scores and suppressed the development of interstitial fibrosis compared with the UW and $\mathrm{N}_{2}$ groups at 100 days after KTx (Figure 4). 
a

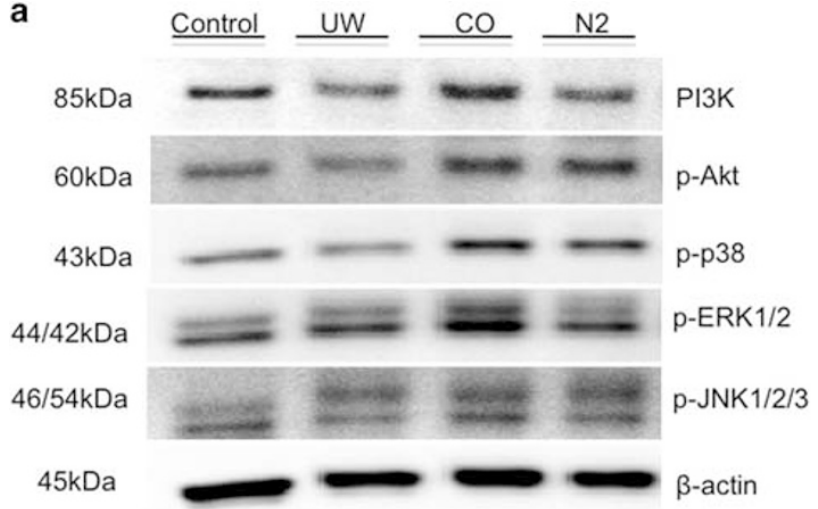

b

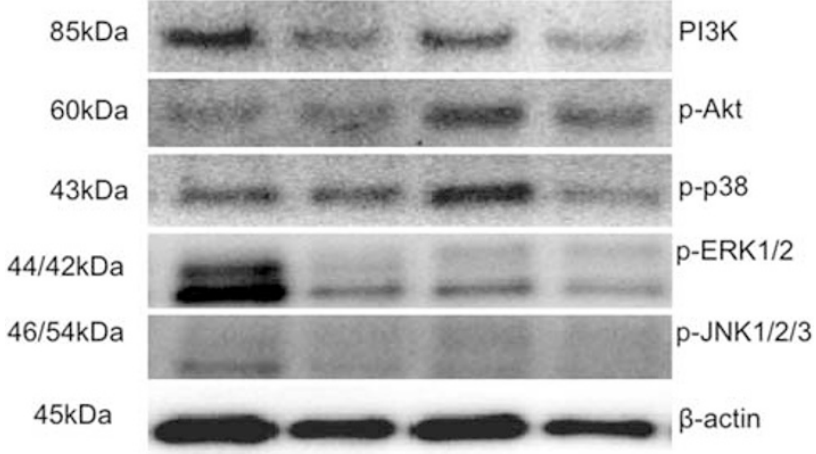

Figure 6 Effect of carbon monoxide on cell signaling. To examine the intracellular CO signaling implicated in tubular protection, the expression of PI3K and the activation of Akt and MAPK were examined at 3 (a) and $24 \mathrm{~h}$ after kidney transplantation (b). Western blot analysis demonstrated that treatment with CO increased PI3K and Akt and p38 MAPK phosphorylation.

We demonstrated that during the early phases, CO treatment decreased oxidative stress and mRNA expression of proinflammatory cytokines, thereby inhibiting tubular apoptosis. CO-mediated activation of p38 MAPK exerts an anti-inflammatory effect. ${ }^{23}$ In the present study, $\mathrm{CO}$ selectively activated p38 MAPK but had no effect on ERK1/ERK2 or JNK MAP kinases (Figure 6). Consistent with these findings, we also found that $\mathrm{CO}$ treatment decreased IFN- $\gamma$ and iNOS mRNA levels after cold I/R injury. Furthermore, our data show that tubular apoptosis was stimulated during cold ischemia and after reperfusion, whereas CO significantly inhibited tubular apoptosis (Figure 5). We demonstrated that $\mathrm{CO}$ treatment increased PI3K, and, induced Akt phosphorylation after cold I/R injury. Several downstream targets of Akt (such as E2F, c-myc, Bad) have been implicated in cell cycle progression and anti-apoptosis. ${ }^{24}$ Activation of Akt protects a wide variety of cells from apoptosis. Thus, our results indicate that the suppressive mechanism of tubulointerstitial injury may be associated with the anti-apoptotic effect, through the PI3K-Akt pathway. One of the major events in I/R-induced kidney injury is the generation of

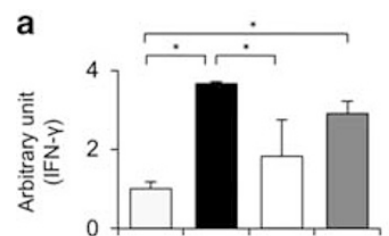

b
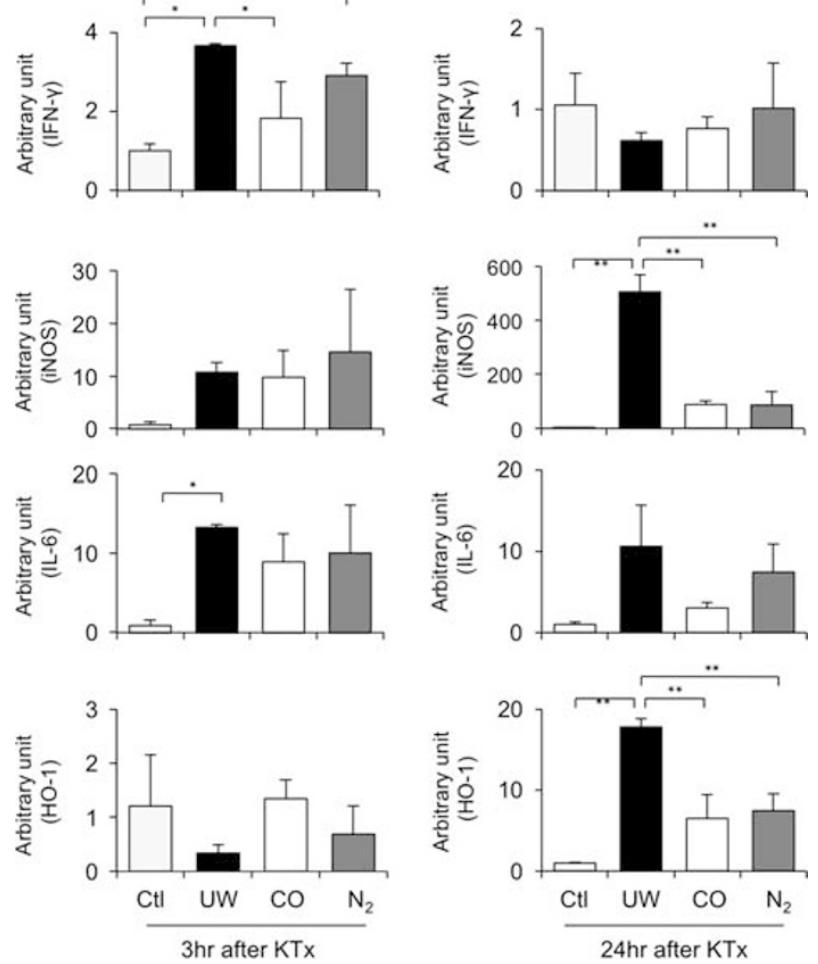

Figure 7 Cortical mRNA expression by real-time RT-PCR assay. The relative mRNA expression of interferon (IFN)- $\gamma$, inducible nitric oxide synthase (iNOS), interleukin (IL)-6, and heme oxygenase-1 (HO-1) at 3 (a) and $24 \mathrm{~h}$ after kidney transplantation (b) is shown. Changes in mRNA expression vs one sample of the control group were calculated. The relative quantity is presented as the ratio of the comparative cycle threshold $(\mathrm{Ct})$ of the target genes against those of housekeeping gene 18. Data are representative of three independent experiments and indicate the mean ratio of triplicate results from each experiment. Data are expressed as means \pm s.d. Tukey's test, ${ }^{*} P<0.01,{ }^{*} P<0.05$.

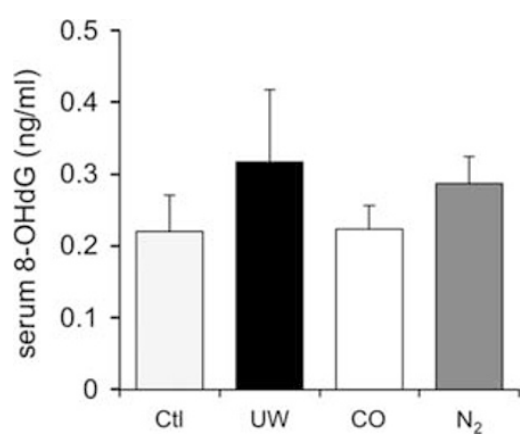

Figure 8 Carbon monoxide ameliorates serum levels of 8hydroxydeoxyguanosine (8-OHdG). Serum levels of $8-\mathrm{OHdG}$, an oxidative stress marker, at $3 \mathrm{~h}$ after kidney transplantation are shown. Prolonged cold ischemia for $24 \mathrm{~h}$ resulted in an increase in 8-OHdG serum levels, whereas CO treatment ameliorated oxidative DNA injury. Data are expressed as means \pm s.d ( $n=3$ /group).

cytotoxic oxygen radicals. ${ }^{25}$ An increase in cytotoxic oxygen radicals leads to increased cellular injury, including DNA damage, protein oxidation and nitrosylation, lipid peroxidation, and apoptosis. ${ }^{26}$ We examined serum 8-OHdG levels to 
evaluate the effects of $\mathrm{CO}$ on oxidative stress (Figure 8). Prolonged cold ischemia for $24 \mathrm{~h}$ resulted in an increase in serum 8-OHdG levels at $3 \mathrm{~h}$ after KTx, whereas $\mathrm{CO}$ treatment ameliorated oxidative DNA injury, suggesting that CO treatment during cold storage reduced injurious reactive oxygen species (ROS). Several possible mechanisms have been postulated to explain the antioxidant effects of CO. Nakao et $a l^{18}$ demonstrated that $\mathrm{CO}$ in the organ preservation solution used during transplantation binds to and stabilizes renal cytochrome P450 (CYP) and prevents CYP degradation and detrimental heme/iron release in renal grafts. Brugger et $a^{27}$ demonstrated that the antioxidant effects afforded by $\mathrm{CO}$ involve activating the p38 MAPK pathway. In this study, it was unclear whether CO suppressed oxidative stress directly or indirectly, but applying CO resulted in suppression of oxidative stress and inhibition of inflammation and apoptosis. Furthermore, several recent studies have shown that CO mediates cytoprotection through the induction of HO- $1.28,29$ However, in this study, endogenous HO-1 was upregulated in kidney grafts preserved with UW solution, whereas COtreated kidneys showed less HO-1 expression. These results suggest that endogenous HO-1 expression is associated with renal graft injury, and that the cytoprotective effect of $\mathrm{CO}$ does not depend on HO-1 activation.

Oxygenation of the preservation solution is mandatory during hypothermic machine-perfusion of abdominal organs. Hart et $a l^{30}$ demonstrated better results with $21 \%$ and $95 \%$ oxygenation, compared with preserving a rat liver without oxygenation in a UW machine-perfusion solution. In addition, they showed that toxic ROS are generated not only during warm incubation but also during cold preservation, and that $21 \%$ oxygen saturation produced optimal results. With the aim of achieving organ preservation under better conditions, we attempted to adjust the optimal gas partial pressure and selected a mixed gas composed of $\mathrm{PCO}=2000 \mathrm{hPa}+\mathrm{PO}_{2}=1500 \mathrm{hPa}$ for kidney graft preservation.

However, $\mathrm{CO}$ binds hemoglobin with an affinity that is 240 times greater than that of oxygen, thereby interfering with the oxygen delivery system of the body. $\mathrm{CO}-\mathrm{Hb}$ levels correlate well with clinical symptoms of CO poisoning in humans; levels of $10-30 \%$ can cause minor transient symptoms including headache, dizziness, and shortness of breath; death occurs at $\mathrm{CO}-\mathrm{Hb}$ levels between 50 and $80 \% .{ }^{31}$ Our study revealed that ex vivo application of high-pressure $\mathrm{CO}$ slightly increased $\mathrm{CO}-\mathrm{Hb}$ levels at $3 \mathrm{~h}$ after $\mathrm{KTx}$, to $1.10 \pm 0.72 \%$, but levels then dropped to naive LEW rat levels by $24 \mathrm{~h}$ after KTx (Figure $2 \mathrm{~b}$ ), suggesting that our procedure may be clinically acceptable. The safety of our method using high-pressure CO for clinicians and transporters is also confirmed. ${ }^{32}$ When filling the gases into the chamber, $\mathrm{CO}$ gas was not detected directly above the chamber. When opening the valve of the chamber inside the fume hood, CO gas was detected on average 260 p.p.m. at approximately $60 \mathrm{~s}$, decreased at approximately $180 \mathrm{~s}$, and then was barely detectable at approximately $240 \mathrm{~s}$. Meanwhile, CO gas was not detected at any time outside the fume hood.

In conclusion, we successfully preserved rat kidney grafts for $24 \mathrm{~h}$ under high-pressure $\mathrm{CO}$ by protecting tubular epithelial cells from apoptosis and inhibiting inflammation. Our new method of organ preservation is a groundbreaking, safe, and simple strategy that can be applied in the clinical setting.

\section{ACKNOWLEDGMENTS}

The authors are grateful to Astellas Pharma for supplying the UW solution (Viaspan) and thank Mizuki Takeyama for her invaluable technical assistance. This study was supported by research grants from the Ministry of Education, Culture, Sports, Science, and Technology of Japan (Grants-in-Aid 15K20087, 15K10043, 15K20303, 15F15756, 20390349, 21659310, 2109739, 15K10043, 15K20303, 15F15756).

\section{DISCLOSURE/CONFLICT OF INTEREST}

The authors declare no conflict of interest.

1. Gueler F, Gwinner W, Schwarz A, et al. Long-term effects of acute ischemia and reperfusion injury. Kidney Int 2004;66:523-527.

2. Locke JE, Segev DL, Warren DS, et al. Outcomes of kidneys from donors after cardiac death: implications for allocation and preservation. Am J Transplant 2007;7:1797-1807.

3. Summers DM, Johnson RJ, Allen J, et al. Analysis of factors that affect outcome after transplantation of kidneys donated after cardiac death in the UK: a cohort study. Lancet 2010;376:1303-1311.

4. Wolfe RA, Merion RM, Roys EC, et al. Trends in organ donation and transplantation in the United States, 1998-2007. Am J Transplant 2009;9(4 Pt 2):869-878.

5. Zaouali MA, Ben Abdennebi H, Padrissa-Altes S, et al. Pharmacological strategies against cold ischemia reperfusion injury. Expert Opin Pharmacother 2010;11:537-555.

6. Bauer I, Pannen BH. Bench-to-bedside review: carbon monoxide-from mitochondrial poisoning to therapeutic use. Crit Care 2009;13:220.

7. Hatayama N, Naito M, Hirai S, et al. Preservation by desiccation of isolated rat hearts for 48hours using carbon monoxide (PCO $=4,000$ $\mathrm{hPa}$ ) and oxygen $(\mathrm{PO}(2)=3,000 \mathrm{hPa})$. Cell Transplant 2012;21:609-615.

8. Azuma H, Isaka Y, Li X, et al. Superagonistic CD28 antibody induces donor-specific tolerance in rat renal allografts. Am J Transplant 2008;8: 2004-2014.

9. Imamura R, Isaka Y, Sandoval RM, et al. Intravital 2-photon microscopy assessment of renal protection efficacy of siRNA for p53 in experimental rat kidney transplantation models. Cell Transplant 2010;19:1659-1670.

10. Yoshida $\mathrm{Y}$, Hatayama N, Seki K. Study on the preservation with CO $(\mathrm{PCO}=200-2,000 \mathrm{hPa})$, resuscitation, and heterotopic transplantation of an isolated rat heart. Cell Transplant 2009;18:535-540.

11. Hatayama N, Yoshida Y, Seki K. 72-Hour preservation, resuscitation, and transplantation of an isolated rat heart with high partial pressure carbon monoxide gas $(\mathrm{PCO}=400 \mathrm{hPa})$ and high partial pressure carbon dioxide $(\mathrm{PCO} 2=100 \mathrm{hPa})$. Cell Transplant 2010;19:707-712.

12. Yamada K, Miwa T, Liu J, et al. Critical protection from renal ischemia reperfusion injury by CD55 and CD59. J Immunol 2004;172:3869-3875.

13. Morita $M$, Fujino $M$, Jiang $G$, et al. PD-1/B7-H1 interaction contribute to the spontaneous acceptance of mouse liver allograft. Am J Transplant 2010;10:40-46.

14. Kumar S, Bandyopadhyay U. Free heme toxicity and its detoxification systems in human. Toxicol Lett 2005;157:175-188.

15. Nakao A, Sugimoto $R$, Billiar $T R$, et al. Therapeutic antioxidant medical gas. J Clin Biochem Nutr 2009;44:1-13.

16. Zhang X, Shan P, Alam J, et al. Carbon monoxide differentially modulates STAT1 and STAT3 and inhibits apoptosis via a phosphatidylinositol 3-kinase/Akt and p38 kinase-dependent STAT3 pathway during anoxia-reoxygenation injury. J Biol Chem 2005;280: 8714-8721. 
17. Faleo G, Neto JS, Kohmoto J, et al. Carbon monoxide ameliorates renal cold ischemia-reperfusion injury with an upregulation of vascular endothelial growth factor by activation of hypoxia-inducible factor. Transplantation 2008;85:1833-1840.

18. Nakao A, Faleo $G$, Shimizu $H$, et al. Ex vivo carbon monoxide prevents cytochrome P450 degradation and ischemia/reperfusion injury of kidney grafts. Kidney Int 2008;74:1009-1016.

19. Yoshida J, Ozaki KS, Nalesnik MA, et al. Ex vivo application of carbon monoxide in UW solution prevents transplant-induced renal ischemia/ reperfusion injury in pigs. Am J Transplant 2010;10:763-772.

20. Sener A, Tran KC, Deng JP, et al. Carbon monoxide releasing molecules inhibit cell death resulting from renal transplantation related stress. J Urol 2013;190:772-778.

21. Ruan $\mathrm{Y}$, Wang $\mathrm{L}$, Zhao $\mathrm{Y}$, et al. Carbon monoxide potently prevents ischemia-induced high-mobility group box 1 translocation and release and protects against lethal renal ischemia-reperfusion injury. Kidney Int 2014;86:525-537.

22. Martins PN, Reutzel-Selke A, Jurisch A, et al. Induction of carbon monoxide in donor animals prior to organ procurement reduces graft immunogenicity and inhibits chronic allograft dysfunction. Transplantation 2006;82:938-944.

23. Otterbein LE, Bach FH, Alam J, et al. Carbon monoxide has antiinflammatory effects involving the mitogen-activated protein kinase pathway. Nat Med 2000;6:422-428.
24. Datta SR, Brunet A, Greenberg ME. Cellular survival: a play in three Akts. Genes Dev 1999;13:2905-2927.

25. Noiri $\mathrm{E}$, Nakao A, Uchida $\mathrm{K}$, et al. Oxidative and nitrosative stress in acute renal ischemia. Am J Physiol Renal Physiol 2001;281:F948-F957.

26. Rodrigo R, Bosco C. Oxidative stress and protective effects of polyphenols: comparative studies in human and rodent kidney. A review. Comp Biochem Physiol C Toxicol Pharmacol 2006;142:317-327.

27. Brugger J, Schick MA, Brock RW, et al. Carbon monoxide has antioxidative properties in the liver involving p38 MAP kinase pathway in a murine model of systemic inflammation. Microcirculation 2010;17:504-513.

28. Hegazi RA, Rao KN, Mayle A, et al. Carbon monoxide ameliorates chronic murine colitis through a heme oxygenase 1-dependent pathway. J Exp Med 2005;202:1703-1713.

29. Lee BS, Heo J, Kim YM, et al. Carbon monoxide mediates heme oxygenase 1 induction via Nrf2 activation in hepatoma cells. Biochem Biophys Res Commun 2006;343:965-972.

30. $t$ Hart NA, van der Plaats $A$, Faber $A$, et al. Oxygenation during hypothermic rat liver preservation: an in vitro slice study to demonstrate beneficial or toxic oxygenation effects. Liver Transpl 2005;11:1403-1411.

31. Von Burg R. Carbon monoxide. J Appl Toxicol 1999;19:379-386.

32. Hatayama $N$, Inubushi $M$, Naito $M$, et al. Functional evaluation of rat hearts transplanted after preservation in a high-pressure gaseous mixture of carbon monoxide and oxygen. Sci Rep 2016;6:32120. 